\title{
Bringing the Copenhagen Global Climate Change Negotiations to Conclusion
}

\author{
JOHN WHALLEY \\ SEAN WALSH
}

CESIFO WORKING PAPER NO. 2458

CATEgORY 7: TRAde POlicy

NOVEMBER 2008

PRESENTEd AT CESIFo VeniCE SuMMER InSTITUTE 2008, WORKSHOP ON

'EUROPE AND GLOBAL ENVIRONMENTAL ISSUES'
An electronic version of the paper may be downloaded
- from the SSRN website: Www.SSRN.com
- from the RePEc website: Www.RePEc.org
- from the CESifo website: www.CESifo-group.org/wp




\title{
Bringing the Copenhagen Global Climate Change Negotiations to Conclusion
}

\begin{abstract}
In this paper we discuss the global negotiations now underway and aimed at achieving new climate change mitigation and other arrangements after 2012 (the end of the Kyoto commitment period). These were initiated in Bali in December 2007 and are scheduled to conclude by the end of 2009 in Copenhagen. As such, this negotiation is effectively the second round in ongoing global negotiations on climate change and further rounds will almost certainly follow. We highlight both the vast scope and vagueness of the negotiating mandate, the many outstanding major issues to be accommodated between negotiating parties, the lack of a mechanism to force collective decision making in the negotiation, and their short time frame. The likely lack of compliance with prior Kyoto commitments by several OECD countries (some to a major degree), the effective absence in Kyoto of compliance/ enforcement mechanisms, and growing linkage to non-climate change areas (principally trade) all further complicate the task of bringing the negotiation to conclusion. The major clearage we see that needs to be bridged in the negotiations is between OECD countries on the one hand, and lower wage, large population, rapidly growing countries (China, India, Russia, Brazil) on the other.
\end{abstract}

JEL Code: F13.

Keywords: climate change, global negotiation.

John Whalley

Centre for International Governance

Innovation (CIGI)

University of Western Ontario

London, Ontario, Canada

jwhalley@uwo.ca
Sean Walsh

Centre for International Governance

Innovation (CIGI)

University of Western Ontario

London, Ontario, Canada

swalsh@cigionline.org

September 2008

An earlier version of this paper was presented at the CESifo Venice Summer Institute as part of a session on "Europe and Global Environmental Negotiations". We are grateful to the Leibnitz Foundation for support, and to Ray Riezman, Carlo Carrero, Yuezhou Cai, Yan Dong, and Hui Fang Tian for comments. 


\section{Introduction}

In this paper we discuss the global negotiations now underway and aimed at achieving new climate change mitigation and other arrangements after 2012 (the end of the Kyoto commitment period). These were initiated in Bali in December 2007 and are scheduled to conclude by the end of 2009 in Copenhagen. As such, this negotiation is effectively the second round in ongoing global negotiations on climate change and further rounds will almost certainly follow.

We set out the state of play in these negotiations and discuss some of the major negotiating issues. In so doing, we focus on the likelihood of these negotiations concluding in 2009 with significant forward movement relative to what was agreed in Kyoto. We highlight, not only the tight time deadlines involved, but the imprecision of the negotiating mandate and also the relative lack of clear drivers moving negotiators towards a conclusion to the Copenhagen process, unlike the case of trade negotiations.

We also identify a series of further obstacles to the Copenhagen negotiation which go beyond simply the imprecision of the mandate. One is the seemingly inevitable backlog in 2012 of unfulfilled commitments from the Kyoto negotiation ${ }^{2}$ and, along with this, an effective absence of dispute resolution in Kyoto and hence the need for enforcement mechanisms, post-Kyoto, that are much more effective than those that currently exist within the Protocol. We also highlight the growing pressures for accompanying measures to accompany any global climate change agreements, particularly in the area of trade, and also the central issues with the participation of low wage, rapidly growing economies, whose emissions are growing rapidly, and especially China. Among all these issues, the more precise interpretation of 'common yet differentiated responsibilities', the imprecise and vague principle which was agreed to in Kyoto, will be central.

Whether the obstacles we identify prove overwhelming, resulting in only a papered over agreement in Copenhagen, or whether substantial progress can be made depends, in our view, upon a number of factors related to background issues to the

\footnotetext{
${ }^{2}$ See Kyoto Protocol (December 1997), Kyoto, Japan: UNFCCC, COP3.
} 
negotiation. One is whether a perception of growing severity of climate change (increased speed of melt of Arctic sea ice, glacial melt, and other such phenomenon) adds enough momentum to existing political pressures to conclude the negotiation. Another is the strength of the collective desire by most of the parties to the negotiation to underpin international cooperation more broadly, and in other areas (such as trade) with a successful environmental negotiation is another. There is also a likely perceived penalty that non-participant regions and countries may face in other areas such as trade which will also add momentum. A further key factor is what negotiating direction the United States will take after the upcoming election.

Our bottom line assessment is that the task of concluding the Copenhagen climate change negotiating round in any satisfactory way for the key parties involved seems, at this stage, daunting. In addition, the mechanisms to be used to move negotiations forward and the more precise negotiating issues seem disturbingly ill-defined and vague for a negotiation of this scope with a planned conclusion (at the time of writing) of 15 months.

We conclude with a discussion of what may be involved in negotiations beyond Copenhagen and suggest that, de facto, sequential negotiating rounds from Kyoto to Bali and Copenhagen and beyond (much as has occurred in GATT/WTO since 1997) are underway. If past trade negotiations are any precedent, there will likely be a progressive broadening of coverage of negotiations sequentially from round to round. How to broaden beyond Copenhagen will thus be a further central issue and countries' participation in Copenhagen will be influenced by where they see the process going beyond Copenhagen.

Another set of issues will involve growing links to other negotiating areas including trade and finance. We suggest that, eventually, we may see the emergence of joint bargaining simultaneously on trade, finance and the environment, linked within an overall regime structure. This may be a few rounds away, but raises the question of the institutional forum in which such global bargaining might occur. For the moment, global policy bargaining has been concentrated in the WTO and limited to trade bargaining. With linked bargaining covering trade, finance and the environment, some wider bargaining format going beyond the current structure of the WTO could emerge in the next few decades. 


\section{The Current State of Copenhagen Negotiations}

2.1 The United Nations Framework Convention on Climate Change (UNFCCC) and PreKyoto International Negotiation on Climate Change

Modern concern over environmental issues began several decades ago and Rachel Carson's Silent Spring (1962) was one of the earlier publications to raise public awareness on these issues. International attention on environmental issues followed and the UN Environmental Program (UNEP) emerged from the Stockholm conference just over a decade later in 1973. UNEP was to research, assess environmental impacts and issues and provide advice to agencies and governments in dealing with them. However, UNEP lacked sufficient mandate and budget, and global environmental issues truly received international attention only with the later discovery of holes in the ozone layer and the subsequent negotiation of the Montreal Protocol, which entered into force in $1989 .^{3}$

During the negotiation of the Montreal Protocol, discussions took place within several international forums as to what the next steps should be on global environmental arrangements. In December 1988, the UN General Assembly requested the World Meteorological Organization (WMO) and UNEP, through their new, jointly created subsidiary institution, the Intergovernmental Panel on Climate Change (IPCC), to think through what potential elements a possible convention on climate change could contain. The role seen for the IPCC was to assess the latest scientific, technical and socioeconomic literature produced worldwide relevant to the understanding of the risk of human-induced climate change, its impacts and options for adaptation and mitigation.

Subsequently, with the release of the First IPCC Assessment Report (FAR) in 1990, the UN established the INF/FCCC, the Intergovernmental Negotiating Committee for the Framework Convention on Climate Change. This body was to prepare a framework convention on climate change and was given 18 months, so as to allow the

\footnotetext{
${ }^{3}$ Details of this Protocol, mainly covering halogenated hydrocarbons and similar ozone depleting substances, can be found on the UNEP website ( http://www.unep.org/OZONE/pdfs/MontrealProtocol2000.pdf )
} 
framework convention to be opened for signature at the Earth Summit in Rio de Janeiro (June, 1992).

Within the initial INF/FCCC discussions, many of the lay concepts currently under discussion as part of a post-Bali arrangement first arose. For instance, the concept of 'common yet differentiated responsibilities' arose as part of the INF/FCCC's mandate to draft a framework that could be supported by a consensus by at least 150 countries. As will be seen later, the exact meaning and interpretation of this term is now a source of much debate in more current discussion and negotiation. Additionally, issues of technology transfer, binding commitments, and general timetables were also discussed and made part of the emerging framework convention.

In 1992, the efforts of the INF/FCCC led to the creation of the UN Framework Convention on Climate Change (UNFCCC), which opened for signature that same year and came into force in 1994. The INF/FCCC dissolved with the first annual Conference of the Parties (COP) to the UNFCCC in Berlin, 1995 (also known as COP1). To date, 192 countries have taken membership in the UNFCCC, 154 of which signed at introduction in 1992. In COP1, a 2-year assessment period was agreed to give countries time to assess options. In part, this was due to the release of a second report by the IPCC that same year. This is the so-called 'Berlin Mandate'. And from this period of initial negotiation, the need for flexibility in any negotiated arrangements was highlighted by developed countries, most notably the US, to balance environmental gains and economic costs.

\subsection{The Kyoto Protocol}

The Kyoto Protocol evolved from the Berlin Mandate's 2-year assessment period, with negotiations and discussion cumulating in negotiations at COP3 in Kyoto, 1997. The Protocol was still unfinished at this meeting and consequentially, only 84 countries signed the Protocol at Kyoto. Two major issues kept several countries from signing on in this initial phase; these were a lack of an enforcement mechanism and that the Protocol still lacked the actual operational details as to how it would function. 
The basic underlying principle to the Kyoto Protocol is greenhouse gas reduction, with a specific focus on carbon dioxide $\left(\mathrm{CO}_{2}\right)$ emissions. Country specific targets (both quantitative targets and time frames) for $\mathrm{CO}_{2}$ emission reduction/ limitation (with reductions in other greenhouse gases measured directly proportional to their greenhouse potency relative to $\mathrm{CO}_{2}$ ) were agreed to and, for the most part, it was left to individual countries to choose the method they would use to implement their targets. The earlier concept of 'common yet differentiated responsibilities' is evident in the variation of cuts agreed to by the various signatory countries. Those with the deepest cuts to make are the UNFCCC's Annex 1 countries, a list which includes most of the world's developed countries. ${ }^{4}$ Developing countries took on no obligations under Kyoto.

Discussion followed on the Protocol's operational details after COP3. The COP was to finalize these details at COP4 in Buenos Aires in 1998, but, negotiations continued until COP7 in Marrakech in 2001. Two inter-related issues were the main stumbling blocks: flexibility in meeting $\mathrm{CO}_{2}$ reduction targets and including carbon sinks as a substitute for emissions reduction. These were advocated strongly by several developed countries, including the $\mathrm{US}^{5}$, so as to allow countries to meet obligations while minimizing harm to national economies. These ideas were incorporated into an amended Kyoto text, which ultimately became known as the Marrakech Accords. After the Accords were negotiated, several more countries subsequently agreed to sign the treaty, the most notable exception being the US. This was the last major amendment to the Kyoto Protocol and, to date, 182 parties (counting the EU as a single entity) have signed and ratified it.

Currently, the Kyoto Protocol sets binding targets for 37 industrialized countries plus the European community for reducing greenhouse gas emissions. On a global scale, these commitments average to a reduction of 5\% against 1990 levels of greenhouse gases over the life of the treaty, which, while written in the Protocol as 2008-2012 (the enforceable period), effectively began the year following the close of the Marrakech Accords negotiation in 2002.

\footnotetext{
${ }^{4}$ The most current version of this list can be found on the UNFCCC website at: http://unfccc.int/parties_and_observers/parties/annex_i/items/2774.php

${ }^{5}$ Eventually, the US rejected the Kyoto Protocol entirely and distanced itself from the negotiation, becoming an observer.
} 
How emission reduction targets are met has been left mostly at the discretion of the individual Protocol signatories. However, 3 mechanisms were included as part of the Protocol in order to facilitate these efforts, add flexibility, allow for ease in starting carbon reduction projects and also add a measure of transparency to them. The UN Climate Change Secretariat keeps a record of all projects and transactions occurring under these mechanisms.

One is the Emissions Trading System (ETS), otherwise known as the carbon market, which allows all those countries with commitments under the Protocol (those within the Protocol's Annex B) that have gone beyond their agreed targets to sell their spare carbon emissions rights to those countries which still need to meet their targets in the international market. Another mechanism is CDMs, or Clean Development Mechanisms. These are projects any Annex B country can initiate and involve low or zero-carbon development initiatives, as well as development directed at adaptation to climate change, in developing nations. These projects are carefully screened before initiation, assessed for their results and, finally, the initiating country is given an allotment of certified emission reduction credits (CERs), which are rights that each allow one tonne of additional carbon to be emitted and can also be sold in the ETS. A notable feature of this mechanism related to funding for these projects is the Adaptation Fund, into which all ongoing projects must contribute a share to their proceeds in order to provide seed money for promising projects and for the support of relatively important ongoing projects.

Finally, the last mechanism is Joint Implementation (JI). This is similar to CDM in concept but it can only occur between two Annex B countries, and thus there are significant differences in the basic approval process, relatively less screening of the projects by international authorities and no fund especially mandated for their support, although the Adaptation Fund may be petitioned for funds if the host Annex B country is also classified as a developing country. Given approval of the host Annex B country, another Annex B country can initiate a carbon reduction project there. Emission reduction units (ERUs) are earned instead of CERs by the country conducting the project (or divided between countries if two or more are involved in the actual project), with the only real difference from CERs being that ERUs cannot be sold. The host country's 
additional benefits lie in any foreign direct investment generated and potential technology transference. Outside of individual country actions aimed at complying with the Protocol, these are the basics of how the Kyoto Protocol would operate, as laid out after amendment by the Marrakech Accords.

The remaining element, enforcement and compliance mechanisms, was little discussed in the original version of the Protocol and while it was a topic of discussion in the Accords negotiation, relatively little was agreed to. The Accords outline a monitoring system for carbon accounting, governed by the UN, and that countries in non-compliance (ie- failure to accurately record their progress and/or a failure to reach their 2012 emissions target) could be removed from the ETS and also have their reduction quotas increased to $130 \%$ of the original target. However, these penalties seem of little consequence to a country not intending to seriously cut emissions in the first place.

As the situation has evolved from 2002 on, only in part due to this lack of effective enforcement, it has become increasingly likely that a large number of developed countries will fail to meet their targets by 2012 . With so much difficulty in achieving significant emission reductions through the Kyoto Protocol it has increasingly become largely symbolic more than effective policy. This is especially so in light of sharp increases in emissions in non-participating low wage, high population, rapidly growing economies such as China and India. As time passed, these developments only served to emphasize the need to move forward to a new treaty, one which would ideally remedy the inherent weaknesses of the Kyoto Protocol. This was evident at COP11, the first meeting of all Kyoto Protocol parties after its initial signing, where the Montreal Action Plan was crafted. This was essentially a formal announcement stating that climate change efforts must continue past 2012, when the Kyoto Protocol expires.

\subsection{The Bali Roadmap and It's Four Pillars of Negotiation}

The Bali meeting (COP13) in December 2007 is the most recent step on the path to a post-Kyoto agreement. In the final hours of negotiation, several agreements were reached which effectively form what was named at the end of the negotiation the 'Bali 
Roadmap, ${ }^{6}$ One component of the Roadmap is the creation of an 'Ad-hoc Working Group on Longterm Cooperative Action under the Convention' (AWG), which is to work on issues outlined in the Roadmap outside of, but parallel to, the Kyoto process. There is thus an official process and a designated group who both work on the same problems.

Some key emitters, most notably the US and China, did not commit to any emissions reductions under Kyoto. Thus, widening the scope of the negotiation to include as many countries as possible, and especially high emitters, was seen as a critical need for any post-Kyoto agreement. At the request of the US and as a prerequisite for their involvement, inclusion of developing countries (and China in particular as an emitter of carbon roughly on the same scale, year by year, as the US) was also deemed to be necessary to moving forward in any significant way on the path defined by the Roadmap. As things now stand, it is still a matter of speculation as to whether either the US or China will participate in future negotiation, with many issues still unresolved, as will be seen in the fourth section. Country membership uncertainties aside, there was also a recognition in the Roadmap that industry, and specifically industry-government collaboration, will likely play a major role in the potential success (or failure) of any negotiation. The view that a one-size-fits-all approach to climate change is inappropriate prevailed, and, hence the participation of industry leaders was also seen as important to help design the region-specific details of any new agreement.

The Bali Roadmap concentrates on four central pillars of future negotiation, which define 4 different goals and possible actions required for each to come about. These are mitigation, adaptation, innovation $\&$ technology transference, and finance \& investment. The roadmap's design is intended to be such that activities under each pillar support activities in one or more of the others. ${ }^{7}$

Mitigation is essentially concerned with damage minimization from climate change. Thus, in essence involves balancing economic cost vs. environmental gain. The conclusion made at Bali was that the Kyoto Protocol was too simplistic in terms of country divisions for required action. A more nuanced approach to designing mitigation

\footnotetext{
${ }^{6}$ More information on the decisions reached at Bali can be found on the UNFCCC official website at http://unfccc.int/meetings/cop 13/items/4049.php

${ }^{7}$ The text for all the agreements reached at Bali may be found at: http://unfccc.int/resource/docs/2007/cop13/eng/06a01.pdf
} 
targets was recommended, which will likely go beyond emissions reduction and encompass other commitments such as energy consumption targets, renewables targets, and others. This broadening of targets is especially relevant for the developing countries whose economies are growing rapidly and in transition to industrialization, but this broadening of measures is also aimed at increasing compliance with agreed targets among all participants.

The adaptation pillar is largely about changing the way that development is viewed as a process, essentially incorporating knowledge of the likely effects of climate change into any development and/or preservation (land, biodiversity, etc.) decisions. Some of this will have to do with planning for changing weather patterns and sea level rise of up to 10 feet by the end of this century, going by some of the more extreme estimates. Transfer of funds to compensate for the costs of adaptation is also a major component. At Bali, the major adaptation concern was for developing countries, as these will be among the most and earliest affected. Country cooperation was emphasized as necessary to allow the emerging effects of climate change, both detrimental and otherwise, to be identified and dealt with.

Another set of concerns at Bali focus on technology and innovation. The development of new and 'greener' technology was seen as the long term solution to climate change. At present, many diverse technologies are being developed around the world, but the problem remains of how to pick and choose among them. Of even greater concern is how to diffuse those technologies quickly on a global scale, especially to developing countries. The Bali Roadmap calls for the creation of incentives to both innovate and transfer technology and also for the removal of obstacles within countries which retard further innovation internationally, giving specific attention to incentives for diffusion to developing countries. Issues surrounding intellectual property rights, technology transfer, infrastructure \& the absorptive capacity of developing countries, and other key issues are left for individual countries to deal with, with assistance from international bodies being largely limited to financial support.

Finally, there is the role of finance and investment, which is central to the other three pillars, as heavy amounts of investment are required to undertake all the actions outlined above. As potentially one of the most vulnerable areas of climate change impacts 
and also as a lynchpin for the financing of climate change related projects in the other three pillars, protection of the finance and investment sector is critical. However, climate change falls well out of the area of expertise of the sector, in general, and hence, there is little going on within it to safeguard the sector's continued wellbeing from climate change effects. There is some financial innovation being done to adapt to green initiatives and protect against climate disasters, but the scale and progress of these efforts are almost certain to be insufficient. While the financial map of climate change related investment is constantly changing, current investment levels after all international funds are figured in are, at best, still in the hundreds of billions of US dollars. ${ }^{8}$ A substantial sum, but to put that in perspective, the International Energy Agency (IEA), in one of their recent books ${ }^{9}$, has estimated that roughly $\$ 45$ trillion USD (or 1.1\% of global GDP annually out to 2050) worth of investment in new green technologies will be needed to reach the longterm goal of $50 \%$ emission reduction by 2050 . And, although there will undoubtedly be beneficial spillovers if investment reaches this level, this figure primarily concerns just one of the four pillars - technology and innovation. Given this distant goal, the primary conclusion at Bali was that, using CDMs, JI, the ETS and by other such means, governments must support innovation in the finance and investment sector and, where possible, help simplify the issues to allow them to be more easily incorporated. Few specifics were agreed to though and so most progress in line with these conclusions will be at the discretion of individual countries.

Institutionally, the four pillars have been provided for. The technology \& innovation pillar has been given primarily to the Expert Group on Technology Transfer (EGTT), a subsidiary institution of the UNFCCC to manage, with financial matters pertaining to this pillar being handled primarily by the Global Environment Facility (GEF). The GEF has also been the named as the temporary secretariat for the adaptation pillar although several institutions, such as the World Bank, also contribute in this area. Beyond this, the pillars of mitigation and finance $\&$ investment are much less localized by nature, with various institutions contributing in several ways but with no institute standing in as a lynchpin for the efforts ongoing.

\footnotetext{
${ }^{8}$ The largest funds will be briefly examined in section 4.6.

9 IEA (2008) "Energy Technology Perspectives 2008: Scenarios and Strategies to 2050"
} 
Two international funds have perhaps contributed to the centralization of the efforts in the adaptation and technology \& innovation pillars relative to the mitigation and finance $\&$ investment pillars. These two large funds are the Adaptation Fund, which was created under the Kyoto Protocol, mandated by the Roadmap and is managed by the GEF (hence their current secretariat role for that pillar), and the Clean Technologies Fund (CTF), which was created independently by the World Bank. Comparatively, funds created for the mitigation and finance $\&$ investment pillars have received much less attention and are almost all national or sub-national in nature. These funds will be discussed in more detail in a later section.

As a final note, the main body of the UN has stated that it will handle all conflicts that arise due to climate change effects, such as the ongoing conflict over ownership of the Arctic and the natural resources therein. Also, while the World Bank's role has been mentioned already, it has become evident that all of the Bretton-Woods institutions are already thoroughly enmeshed in these activities, with the IMF offering what expert advice it can to all parties and within the WTO, talks are ongoing as to the possibility of integrating the international trade and environment regimes.

\subsection{Beyond Bali: Poznań and Copenhagen}

At Bali, it was understood that a final agreement was still out of reach by the end of the negotiation and the goal set out for having a new post-Kyoto climate change treaty was two years later at COP15 in Copenhagen, set to happen November $30^{\text {th }}-$ December $11^{\text {th }}, 2009$. The four pillars laid out at Bali are just as stated: the main part of a roadmap, meant to simply encompass the general shape of what that final treaty may look like. The stated purpose of the next two COPs at Poznań in December 2008 and at Copenhagen itself is to give better definition to what the final post-2012 agreement will ultimately be, to fill in the details within the general shape of the Bali Roadmap, and to garner as much support for a post-Kyoto climate change agreement as possible. However, there are a great many issues still left to be resolved, perhaps too many to be left for these two conferences. Thus, even before Poznań, intern discussions are occurring frequently both 
within all four pillars as well as in more general terms and, while general agreement to a post-Kyoto regime is high, there are several outstanding issues before an agreement can feasibly be reached in Copenhagen, with very few having been resolved. Most of the largest issues have to do with redefining what 'common yet differentiated responsibilities' means, which ultimately requires a resolution to the dispute on what the roles of the developed, industrializing and least developed countries each should be in dealing with climate change. In other words, to what extent does development towards economic, social, cultural and other key goals within a country take precedence over environmental considerations for each country? A difficult ethical question to be sure, especially when the last few hundred years of any given country's history also weigh into any discussion on this question.

But beyond ethics, another (more pragmatic) issue concerns the effectiveness of any new agreement and almost always key in several discussions regarding this issue is the involvement of three key emitters in the negotiations who did not agree to or were not required to take action under Kyoto: the US, India and China. Most discussion regarding the US, the top emitter in the developed world, stops with their upcoming presidential election. There seems to be a tacit agreement to wait and see what the next president will do before moving forward with that discussion. As to the Chinese, on a level basis they are emitters on a very similar scale to the US, and thus, citing the potential damage to their economy otherwise, have stated that they will not participate unless the US does as well. Another issue is that the Chinese would prefer emissions to be measured on a per capita scale rather than the current practice of measuring on a level scale since, on a per capita basis, China has a much lower emissions level than the US despite being roughly equal on a level basis. ${ }^{10}$ The case of India is similar to China's, but more general. India resents the West's view that they must reduce emissions to an extent that it harms their economy and social programs while the West has yet to get serious about emissions themselves, essentially taking a stance that challenges the West by stating India will get serious about emissions if the developed world will. In the words of a former

\footnotetext{
${ }^{10}$ There is a case to be made for either method of measurement - either level or per capita. Intrinsically, the atmosphere does not care about per capita emissions, only those on a level basis. However, given the varying size and population density of countries around the world, a per capita basis is much more fair in terms of burden sharing.
} 
Environment Secretary of India, Pradipito Ghosh, "The prime minister [Dr Manmohan Singh] has said that while pursuing our policies of development and poverty alleviation, we will ensure that our per capita emissions will never exceed developing countries," ... "This is our challenge to the West. 'You do the best you can, and we'll match it'."11

Another significant portion of this intern discussion and negotiation will be dedicated to an attempt at resolving the differences between the current trade regime and environmental policy. The differences between the two regimes are such that some have already suggested that they are incompatible. They reflect the fact that the current international framework, centered on the Bretton-Woods institutions, was not designed to take into account any possible physical linkages between countries. Only matters pertaining to political and economic linkages were considered key at the time of their creation in the 1940's. As a result, and what alarms trade specialists so much, is that environmental aims almost inevitably seek to impose limits on trade entirely outside of the WTO process in order to control the flow of carbon and price products with a high level of carbon embodied in their production accordingly. These additional costs have no basis within the current WTO structure and can only be classified as an unsanctioned tariff within it. Thus, trade specialists see the emerging environmental regime as a major threat to the continuation of the current trading regime under the WTO.

As such, to ward off a failure within one of these regimes when the pressure becomes too much, a measure of integration would be the obvious solution. Ultimately, this will involve a great deal of complex negotiation on such issues as international investment, border tax adjustments and embedded carbon, and thus potentially, a major shift in how the international system works. We could see, for example, a new World Environmental Organization emerge, which would change the dynamics of the global system. ${ }^{12}$ More drastically, we could also see the emergence of an entirely new global order from this negotiating process depending on the course of global warming over time and, assuming significant progress ${ }^{13}$, there is a greater and greater call for action. However, the negotiations have a great deal of progress to make and many obstacles to

\footnotetext{
${ }^{11}$ See http://www.telegraph.co.uk/earth/main.jhtml?xml=/earth/2007/06/12/eaindia12.xml

${ }^{12}$ See Whalley \& Zissimos $(2000,2001)$

${ }^{13}$ One event that would cause a sufficient amount of worry and spur this type of action is an ice-free Arctic, predicted to occur anywhere between 2013 and 2050 depending on who you ask. Any climactic event of sufficient proportions to worry people on a global scale may also spur action of some sort.
} 
deal within a limited time frame in order to design even a single successor treaty to Kyoto, let alone solutions involving more drastic measures, as will be seen in a following section. 


\section{Broad Issues for the Negotiation Process in Copenhagen}

The negotiations in Copenhagen are the second round of global climate change negotiations following their first initiation in Kyoto in 1997. As such, they are parallel to the WTO negotiations which effectively began in 1947 with the creation of the GATT, with the GATT as the focal point of a series of successive negotiating rounds which followed. As such, these negotiations need to be seen both in their broader and more narrowly focused perspectives. In the section which follows, we discuss more detailed negotiating issues for Copenhagen. But a number of broader considerations follow first. First and foremost is a discussion of the driving forces behind the negotiation as they relate to its concludability. Clearly, the central issue is the perceived severity of climate change and the potential damage associated with climate change effects as they escalate with temperature change. The perception of damage is critical to the concludability of negotiations. The recent Stern Review (2006) has suggested that the business-as-usual (BAU) scenario could, by 2050, involve global damage in the region of $20 \%$ of global product. This involves an estimate of $5 \%$ of damage stemming from traditional economic damage and $15 \%$ from other sources including social disruption. With damage of this severity, the political momentum and the imperative to negotiations is central. On the other hand, authors such as Mendelsohn (2006) have suggested that, on the basis of detailed analysis of farm-level data in the US and elsewhere, a more realistic estimate of damages may be indistinguishable from zero and Mendelsohn suggests a base-case estimate of damages at $0.1 \%$ of GDP. Clearly, if these damage estimates are taken as central estimates, the political momentum behind climate change negotiations for the next few decades effectively disappears. The perception of damage is therefore key to the negotiating process. Those involved with the UNFCCC process, such as Yvo de Boer, have gone as far as to suggest that the weight of scientific evidence is such that major disruption and damage from climate change is so clear that he has used the terminology that it would be 'criminal' on the part of the politicians of the major countries of the world not to negotiate major climate change limitation.

These differences in perception therefore, are central to the negotiation and, for now, negotiations are being driven by committed individuals in terms of their 
interpretation of the scientific evidence of climate change within the UNFCCC process, within environmental ministries and more broadly, with a seemingly global political consensus of the increasing severity of climate change. As such, for now the political momentum seems strong and almost unstoppable, but that could change with a reevaluation of scientific evidence.

The other feature of broad background is the linkage between climate change regimes and other elements of policy regimes. Climate change negotiations, up until now, have been seen as separate, stand-alone negotiations designed to remedy a problem with an emerging climate regime which can largely evolve independently of the rest of the policy regime. The reality, however, is that the form and scope of social engineering which is implied by the kinds of changes being discussed as part of the Bali mandate is such that every element of economic policy, both within and across countries, will be touched by it in ways that would greatly complicate climate change negotiation. This is already arising centrally in the trade area. There are pressures which have been building in Europe to both deal with so called 'leakage', that is, one group of countries reducing their emissions and this facilitating increases in emissions elsewhere, but more centrally to deal with the anti-competitive effects and costs inflicted on domestic producers associated with significant carbon emissions limitation. In Europe, this has led to calls for border tax adjustments and accompanying measures to supplement the climate change discussions. Climate change, however, reaches far and wide into every dimension of global policy.

There is no reason why climate change negotiations should not only focus on the mitigation elements of the post-Bali Roadmap, but also on burden sharing and the distributional implications of climate change initiatives. One could argue that the country specific risks associated with climate change are extraordinarily unequally distributed and this has been evident in the activities of the 43 AOSIS $^{14}$ small island states who risk disappearance under major sea level rise. In West Africa, there are a large number of small countries with borders running parallel to the ocean and with increased desertification, there would be need for major movement of individuals across borders. It has been argued that these are poor countries who would be unwilling and unable to

${ }^{14}$ AOSIS - Alliance Of Small Island States 
accept such large influxes of refugees without major commitments of foreign aid committed to them in advance on a contingent basis. Such contingent negotiations could therefore involve a major realignment of global aid arrangements. And with aid flows currently running at $0.2 \%$ of GDP from the US and other OECD countries, seemingly massive adjustments in global aid arrangements would necessarily follow.

Trade arrangements would be central in terms of maintaining access to key export markets, particularly for rapidly growing emerging economies. China is a case in point, with 30\% export growth and a development strategy focused centrally on integration into the global economy, growing industrialization and trade. One major concern in China is that climate change negotiations could involve a closing of global markets to them, with the world going both green and protectionist at the same time. From China's point of view therefore, linking trade and climate change negotiations is central in the sense that China may be more willing to take on climate change commitments in return for firmer guarantees of market access.

Global financial markets and the global financial structure will also be altered by the reallocation of risk in light of growing climate change scenarios. Issues of global warming and global flooding bonds and so on would inject a new element into global financial arrangements, which could rapidly overwhelm the structure of the financial system as it exists now.

In all these ways therefore, in terms of global efficiency and distributional impacts, the allocation of risk, the linkage to other countries, the broadening of the focus of climate arrangements beyond simply mitigation, adaptation and the post-Bali Roadmap and into burden sharing therefore are wider elements of this negotiation, and how it builds into future negotiations will be key.

The concludability of this negotiation therefore will be driven in part by the broader context in which the negotiation takes place. If it takes place in a climate of perceived climate of rapidly growing severity of climate change damage, the momentum behind the negotiation will be such that it may well force some form of conclusion. With weaker perceptions that things will change and the complications and difficulties associated with linkage will come into play. 


\section{Substantive Negotiating Issues for Copenhagen}

In this section, we set out our sense of some of the key negotiating issues for the Copenhagen negotiation, which will likely be centered on in the Poznan meetings and, sequentially, in the various COP meetings as the negotiation moves forward. We discuss this through a series of topic sub-headings.

\subsection{Defining a Possible Agreement}

There are several issues still remaining surrounding what the basic characteristics of the agreement could be. One of these concerns the time frame and the base date for the negotiation for the commitments which would be undertaken as a result of the negotiation. In terms of the time frame, at the moment it is unspecified how long commitments undertaken in 2012 will apply for, but it makes a big difference, particularly for the rapidly growing economies, whether this is 10, 15, 20 years or even longer. Related to this is the central issue of the base date for the calculation of commitments. In the Kyoto negotiation, the Kyoto negotiation was given momentum to conclude by the commitment and agreement of Russia to participate, and the agreement of Russia to participate was heavily influenced by the choice of 1990 as the base date because, between 1990 and 1997 there had been an implosion of the Russian economy, with a reduction in income per capita of nearly $40 \%$, and so Russia was able to undertake commitments relative to a 1990 base date, which it could trivially meet. And even today, Russia is still significantly below its 1990 emissions levels.

As a result, in the current negotiation, the Russian position thus far has been one of emphasizing how central it is to the Russian participation in these negotiations to maintain a 1990 base date for any emissions calculations. The choice of the base date may be more important for Russia than the choice of negotiating instrument. On the other hand, for an economy such as China which is rapidly growing, the use of a base date of 1990 would be disastrous due to the growth which has occurred since that time. The 
Chinese incentive is to have as recent a base date as possible. The conflict over these base dates and time frames therefore, will also be a central issue in the negotiations.

Paired with the issue of the time frame is the issue of the depth of the commitments for $\mathrm{CO}_{2}$ emissions within a post-Kyoto agreement. With the levels of $\mathrm{CO}_{2}$ in the atmosphere still on the rise, the required cuts to stay within the safe zone of a 2 degree temperature rise limit, as indicated by the reports of the IPCC, are constantly increasing. Even a year ago the limit for carbon reduction that governments were willing to consider was a $50 \%$ cut by 2050 . In most places this remains the official stance, yet today it is fairly common for (as yet) unofficial declarations of $80 \%$ reduction targets by 2050 to be made in various countries. Largely this is a refection of the direness of the problem as perceived through the lens of the IPCC reports, the Stern Review (2006), and other widely read sources supporting the science of climate change and as time goes on, if the viewpoint in these reports continues to hold sway with the international community, the range of cuts under consideration will likely continue to stay high and possibly even rise beyond $80 \%$. Thus, the depth of the cuts that will be agreed to in Copenhagen will depend on the perceived severity of climate change at the time of the negotiations and whether the science behind such reports continues to hold up against scrutiny.

Another issue is that of the form of the commitments within the agreement. If an agreement is to be reached in Copenhagen, how much emphasis should be placed on emissions reduction and how much on other possible actions? Several other options such forestry protection/ renewal projects, similar projects focused on biodiversity and several others which ultimately go beyond a focus on mitigation by way of carbon emissions reduction exist and could potentially be more effective in the long term. With four key pillars now defined in the Bali Roadmap, ideally each should receive a significant amount of attention in any final agreement as opposed to the Kyoto Protocol's pure focus on mitigation. The inclusion of industry in the post-Bali process is an indication that, at the very least, any agreement reached will aim to be more nuanced than Kyoto in terms of it's required commitments.

However, to complicate this issue even further, it seems that countless countries have already been engaged in unilateral projects to combat and prepare for climate change outside of their Kyoto Protocol commitments. For example, a number of 
economies, such as the EU and China, have unilaterally committed themselves to significant emissions reductions relative to trend (instead of absolute levels) by 2020. The EU have committed themselves to a 20-20-20 program - to achieve a $20 \%$ reduction in emissions and a $20 \%$ use of renewables by 2020 . In the Chinese case it's a $20 \%$ reduction in energy consumption relative to GDP and a $20 \%$ use of renewables, also by 2020 . The question is whether, in the negotiations in Copenhagen, a country should receive some sort of credit in the multilateral negotiation for such unilateral actions. At one level one can still argue that these unilateral actions simply serve as mechanisms to achieve their multilaterally committed targets, but on the other hand, some of the targets which have been specified for unilateral action share no similarity to multilateral commitments. Commitments, for instance, in terms of percentage of renewables, although this would presumably show up in terms of reduced emissions. The general issue then, of credits for unilateral action, is significant.

\subsection{Common yet Differentiated Responsibility}

The first central issue for the Copenhagen negotiation will confront both the participation of large, rapidly growing, low wage economies, especially China but also India and Brazil, as well as the terms for their participation in the negotiation. These countries did not participate in the Kyoto negotiations and now the pressure is for them to be included, especially in the Chinese case since they are poised to become the largest emitter of carbon globally. ${ }^{15}$

These entities have a special situation to deal with in terms of their negotiating positions. First of all, they are rapidly growing and have aspirations to growth and development for poverty alleviation and significant improvements of levels of wellbeing within their economies. In order to achieve this, any negotiated commitments by them in the climate change area have to allow them room to grow. As such, both the format and form of commitments that they may be asked to take on will inevitably be different from

\footnotetext{
${ }^{15}$ Refer to recent International Energy Agency’s World Energy Outlook reports \& associated press releases: http://www.worldenergyoutlook.org/
} 
those that apply to mature OECD economies. In the Kyoto negotiations, this was implicitly recognized with the adoption of the ill-defined principle of 'common yet differentiated responsibilities'.

In the Kyoto negotiation, 'common yet differentiated responsibilities' was widely interpreted to imply that developing countries would not be subject to any commitments in terms of emissions reductions within the Kyoto negotiation and all emissions reductions would be made by OECD economies. 'Common yet differentiated', therefore, meant non-participation by developing countries. In the Copenhagen negotiation, this interpretation of 'common yet differentiated responsibilities' seems no longer to be capable of prevailing, both because of the current emissions from these economies and their rapid growth and hence major debate and discussion will take place over the interpretation of this term and what it's significance is for these economies.

In addition, as we argue later on, these economies are also in a special position of not having undertaken Kyoto commitments and hence not being in the position, as many OECD countries are, of having not met Kyoto commitments. The lack of overhang of non-compliance from Kyoto is therefore also a defining characteristic of these economies.

As far as 'common yet differentiated responsibilities' go, two different interpretations circulate, each of which has major implications for the negotiation. One is an interpretation of 'common yet differentiated responsibilities' to mean that developing countries and these rapidly growing economies should not be expected to take on commitments in terms of climate change and emissions reductions which impinge adversely on their growth and development until they achieve developmental levels comparable to those in the OECD economies. As such, the argument would be that if they take on any environmental commitments, they should receive financial compensation for their environmental restraint. Put differently, these countries have rights to growth and development which override their responsibilities to environmental commitments until such time as they achieve the growth and developmental levels of the OECD. As such, the four pillars take on greater significance in the Copenhagen Round since, effectively, the negotiation is one on emissions reductions plus financial supports and the financial supports should then be seen in the form of financial compensation to developing countries in order to obtain compliance with environmental commitments. It 
is also almost certainly the case that the size and form of these financial commitments would have to go way beyond the current numbers and estimates which circulate for the adaptation funds and the innovations funds. These, in turn, are implicit in the other funds which circulate, either in proposal form or more concretely, outside the Bali process, particularly the Clean Technology Fund, where the target for the UK, Japan and the US is $\$ 30$ billion (USD), with an initial commitment in the region of $\$ 5$ billion to enable this fund to move forward. This far exceeds the figures which are cited for the adaptation and innovation funds.

Hence the first interpretation of 'common yet differentiated responsibilities' would imply that the negotiation in Copenhagen would explicitly link financial compensation for developing countries to any environmental commitments which they are to undertake.

The second interpretation is one where "common yet differentiated responsibilities' refers to the form of commitment which is undertaken. China, India and Brazil have all suggested that negotiations in the Copenhagen process should focus on reductions in emissions intensity rather than reductions in emissions levels, as this would allow room for them to grow. One possible interpretation of 'common yet differentiated responsibilities' is therefore that, in a negotiation concluding in Copenhagen, China, India and Brazil would take on commitments in terms of emissions intensity, whereas the OECD would take on commitments in terms of emissions levels - ie. - the 'common yet differentiated responsibility' translates to differential commitments undertaken by different groups of countries. This is a very central issue, particularly for the participation of these large entities and will almost certainly be a focus of major debate.

\subsection{Choice of Negotiating Instruments}

A second set of issues for the negotiation focus on negotiating instruments. The negotiations which concluded in Kyoto involved commitments to reductions in emissions relative to a specified base date. Almost certainly, the rapidly growing economies of China, India and Brazil would be unwilling to take on commitments on this basis. This is 
simply because these are rapidly growing economies and, to leave room for their growth, commitments on the basis of commitments levels are inconsistent with their growth aspirations. In the $11^{\text {th }} 5$-year plan in China in 2005, China set out their clear objective to quadruple real GDP per capita between 2000 and 2020. A restatement of that objective between 2020 and 2040 and then continued growth after 2050 would apply a thirty-fold increase in GDP per capita over that period of time, with concurrent large increases in emissions independently of the adoption of more emissions-compatible technologies and the reduction in the numbers of small coal burning power plants.

These growth profiles are such then that these economies will clearly argue that negotiations should take place on the basis of emissions intensity rather than emissions levels. This therefore is one central issue in the negotiations, which is the choice of instrument, along with which goes the issue of whether a same and common instrument will be used for all parties to the negotiation.

Another related issue concerns the calculation of liability for emissions reduction and whether it should be related to the use of fossil fuels on a geographical or territorial basis, effectively looking at emissions associated with an economy's production, or whether it should be the consumption within the economy. China, for instance, has argued that approximately $35 \%$ of China's carbon emissions are related to exports. These exports represent the consumption of entities outside China, both in the OECD and elsewhere, and these emissions should be the liability of the entities which enjoy consumption of the goods which are produced, not the liability of China because of the geographical use of production methods. This is an especially large issue for China since China is rapidly becoming the manufacturing center for the world and nearly over $60 \%$ of Chinese GDP now originates in the manufacturing sector. It also raises complex issues of administration and implementation. Were agreements to be made in terms of consumption rather than production as a basis for the calculation of emissions reduction, there would have to be agreements on the calculation of the carbon content and the administration of any carbon content rules. These rules, in turn, would be very complex since they would not only relate to the amount of carbon directly embodied in the production of goods, but also the carbon involved indirectly and components for production would originate in third countries, with multiple shipments in between 
different pairs of countries in the production process. Current estimates are that in the manufacturing sector in China, around 55-60\% of the total value of production of FDI related activities for export are related to imports, that is, the processing trade in these economies is very large and would also have to be reflected in these carbon basis calculations. Hence, a further issue arising with embedment is the basis for the calculation of carbon content. ${ }^{16}$

\subsection{A Backlog of Unfulfilled Commitments}

Yet another issue which is very central to the Copenhagen negotiation is the backlog of unfulfilled commitments under the Kyoto Protocol which will apply, in all probability, to a significant number of OECD economies. Arguably the most severe case is Canada, where some current projections insist that Canada could be $30 \%$ (over 150 million tonnes of $\mathrm{CO}_{2}$ ) beyond their Kyoto commitment targets by 2012 (see Table 1). The central issues that these backlogs of unfulfilled commitments present are, first of all, the credibility of any future negotiating arrangement, that it raises the question of how negotiations can take place with countries on commitments beyond Kyoto when the Kyoto commitments themselves have not been met. It also raises the issue of the enforcement and dispute settlement mechanisms within negotiated arrangements. In Kyoto, only a marginal amount of time was devoted to crafting enforcement mechanisms (which have since proved to be largely insufficient) and the assumption is that parties to a future negotiation will be insistent that much more effective dispute settlement mechanisms are applied. It will also have the effect of dividing the negotiating parties effectively into two groups: those parties which either did not participate in the first negotiating round (China, Russia, India, Brazil), parties which have not ratified their commitments such as the US, and parties who have easily met their commitments such as Russia. These countries will be pitted in a coalition against the countries which are

\footnotetext{
${ }^{16}$ See Walsh \& Whalley (2008). Note also that this is not as advantageous to China as it may seem. As a developing nation, China is a large importer of carbon intensive goods, most notably building materials such as steel and concrete, as well as a large exporter in various manufactured goods. The net effect would thus be much less than simply writing off the $35 \%$ of Chinese emissions attributable to exports and could potentially even increase the net level of emissions China is accountable for.
} 
Table 1:

Changes in GHG emissions from 1990 to 2004 for Annex I Parties

\begin{tabular}{|c|c|c|c|c|c|c|}
\hline \multirow[b]{2}{*}{ Party } & \multicolumn{3}{|c|}{$\begin{array}{l}\text { Total GHG emissions without } \\
\text { LULUCF ( } \mathrm{Tg} / \text { million tonnes } \mathrm{CO}_{2} \\
\text { equivalent) }\end{array}$} & \multicolumn{2}{|c|}{$\begin{array}{c}\text { Changes in emissions } \\
(\%)\end{array}$} & \multirow{2}{*}{$\begin{array}{c}\text { Emission reduction } \\
\text { target under the } \\
\text { Kyoto Protocol }{ }^{\mathrm{a}, \mathrm{b}} \\
(\%)\end{array}$} \\
\hline & 1990 & 2000 & 2004 & 1990-2004 & $2000-2004$ & \\
\hline Australia & 423.1 & 504.2 & 529.2 & 25.1 & 5.0 & $-{ }^{c}$ \\
\hline Austria & 78.9 & 81.3 & 91.3 & 15.7 & 12.4 & $-8(-13)$ \\
\hline Belarus & 127.4 & 69.8 & 74.4 & -41.6 & 6.6 & no target yet \\
\hline Belgium & 145.8 & 147.4 & 147.9 & 1.4 & 0.3 & $-8(-7.5)$ \\
\hline Bulgaria & 132.3 & 64.3 & 67.5 & -49.0 & 5.1 & -8 \\
\hline Canada & 598.9 & 725.0 & 758.1 & 26.6 & 4.6 & -6 \\
\hline Croatia & 31.1 & 25.3 & 29.4 & -5.4 & 16.5 & $-{ }^{c}$ \\
\hline Czech Republic & 196.2 & 149.2 & 147.1 & -25.0 & -1.4 & -8 \\
\hline Denmark & 70.4 & 69.6 & 69.6 & -1.1 & 0.1 & $-8(-21)$ \\
\hline Estonia & 43.5 & 19.7 & 21.3 & -51.0 & 8.4 & -8 \\
\hline European Community & 4252.5 & 4129.3 & 4228.0 & -0.6 & 2.4 & -8 \\
\hline Finland & 71.1 & 70.0 & 81.4 & 14.5 & 16.4 & $-8(0)$ \\
\hline France & 567.1 & 561.4 & 562.6 & -0.8 & 0.2 & $-8(0)$ \\
\hline Germany & 1226.3 & 1022.8 & 1015.3 & -17.2 & -0.7 & $-8(-21)$ \\
\hline Greece & 108.7 & 131.8 & 137.6 & 26.6 & 4.5 & $-8(+25)$ \\
\hline Hungary & 123.1 & 81.9 & 83.9 & -31.8 & 2.5 & -6 \\
\hline Iceland & 3.28 & 3.54 & 3.11 & -5.0 & -12.2 & +10 \\
\hline Ireland & 55.6 & 68.7 & 68.5 & 23.1 & -0.4 & $-8(+13)$ \\
\hline Italy & 519.6 & 554.6 & 582.5 & 12.1 & 5.0 & $-8(-6.5)$ \\
\hline Japan & 1272.1 & 1345.5 & 1355.2 & 6.5 & 0.7 & -6 \\
\hline Latvia & 25.9 & 9.9 & 10.7 & -58.5 & 8.2 & -8 \\
\hline Liechtenstein & 0.229 & 0.256 & 0.271 & 18.5 & 6.0 & -8 \\
\hline Lithuania & 50.9 & 20.8 & 20.2 & -60.4 & -3.1 & -8 \\
\hline Luxembourg & 12.7 & 9.7 & 12.7 & 0.3 & 31.3 & $-8(-28)$ \\
\hline Monaco & 0.108 & 0.117 & 0.104 & -3.1 & -11.0 & -8 \\
\hline Netherlands & 213.0 & 214.4 & 218.1 & 2.4 & 1.7 & $-8(-6)$ \\
\hline New Zealand & 61.9 & 70.3 & 75.1 & 21.3 & 6.8 & 0 \\
\hline Norway & 49.8 & 53.5 & 54.9 & 10.3 & 2.7 & +1 \\
\hline Poland & 564.4 & 386.2 & 388.1 & -31.2 & 0.5 & -6 \\
\hline Portugal & 60.0 & 82.2 & 84.5 & 41.0 & 2.9 & $-8(+27)$ \\
\hline Romania & 262.3 & 131.8 & 154.6 & -41.0 & 17.3 & -8 \\
\hline Russian Federation & 2974.9 & 1944.8 & 2024.2 & -32.0 & 4.1 & 0 \\
\hline Slovakia & 73.4 & 49.4 & 51.0 & -30.4 & 3.3 & -8 \\
\hline Slovenia & 20.2 & 18.8 & 20.1 & -0.8 & 6.6 & -8 \\
\hline Spain & 287.2 & 384.2 & 427.9 & 49.0 & 11.4 & $-8(+15)$ \\
\hline Sweden & 72.4 & 68.4 & 69.9 & -3.5 & 2.1 & $-8(+4)$ \\
\hline Switzerland & 52.8 & 51.7 & 53.0 & 0.4 & 2.6 & -8 \\
\hline Turkey & 170.2 & 278.9 & 293.8 & 72.6 & 5.3 & $-{ }^{c}$ \\
\hline Ukraine & 925.4 & 395.1 & 413.4 & -55.3 & 4.6 & 0 \\
\hline United Kingdom & 776.1 & 672.2 & 665.3 & -14.3 & -1.0 & $-8(-12.5)$ \\
\hline United States & 6103.3 & 6975.9 & 7067.6 & 15.8 & 1.3 & $-{ }^{c}$ \\
\hline $\begin{array}{l}\text { Annex I EIT } \\
\text { Parties }\end{array}$ & 5551.0 & 3366.9 & 3506.0 & -36.8 & 4.1 & - \\
\hline $\begin{array}{l}\text { Annex I non-EIT } \\
\text { Parties }\end{array}$ & 13000.5 & 14147.7 & 14425.6 & 11.0 & 2.0 & - \\
\hline $\begin{array}{l}\text { All Annex I Parties to } \\
\text { the Convention }\end{array}$ & 18551.5 & 17514.6 & 17931.6 & -3.3 & 2.4 & - \\
\hline $\begin{array}{l}\text { Annex I Kyoto } \\
\text { Protocol Parties }\end{array}$ & 11823.8 & 9730.3 & 10011.5 & -15.3 & 2.9 & -5 \\
\hline
\end{tabular}

"The national reduction targets as per the "burden-sharing" agreement of the European Community are shown in parentheses.

${ }^{b}$ The national reduction targets relate to the first commitment period under the Kyoto Protocol, which is from 2008 to 2012 .

${ }^{\circ}$ A Party to the Climate Change Convention but not a Party to the Kyoto Protocol.

Note: base year data (under the Climate Change Convention) are used here instead of 1990 data (as per COP decisions 9/CP.2 and 11/CP.4) for Bulgaria (1988), Hungary (average of 1985-1987), Poland (1988), Romania (1989) and Slovenia (1986).

Source: UNFCCC website, accessed Sept 10, 2008.

http://unfccc.int/files/essential_background/background_publications_htmlpdf/application/pdf/ghg_table 0 $\underline{6 . p d f}$ 
significantly in violation of their compliance to Kyoto commitments. And the pressure, presumably, will be on countries to honor their commitments to unfulfilled Kyoto pledges as part of the Copenhagen process going forward beyond 2012. Hence, the prospect is for a group of countries, of whom Canada is the most severe, to carry forward with them their unfulfilled commitments from Kyoto as well as any further negotiated cuts which they undertake as part of the Copenhagen process. This is a central issue and also relates to the issue of dispute settlement.

\subsection{Accompanying Measures \& Spillovers Beyond the Environmental Regime}

Although not explicitly stated in this way in the Bali Roadmap, there are growing pressures in the emerging discussion for there to be accompanying measures which would be introduced or allowed alongside the Bali/Kyoto/Copenhagen commitments so as to allow implementation of the commitments. These arise centrally and explicitly in the trade area. For now, these issues have most centrally been discussed and debated in the European case, but these discussions are beginning to spread. The catalyst behind them in the European case is not only the prospect of a new international regime in 2012 beyond Copenhagen and Bali, but also the impending changes which will occur in the European trading scheme for carbon emissions, which, from 2012, will move from what is heavily a cap-and-trade system, where existing producers receive an allocation of rights to emit carbon comparable to their current use, with a requirement to buy additional permits, to one in which there is effectively full auctioning of permits so that producers will have to buy permits for all carbon emissions. This potentially generates significant new cost pressures for European producers and has been the source of much discussion of proposed border tax adjustments in Europe which will accompany these new arrangements and the pressures are building for the same border tax adjustment issues to be debated as part of the Copenhagen/Bali process.

In essence, the argument is that if certain economies view themselves as going farther and faster in terms of environmental commitments and others, this imposes a cost disadvantage on their domestic producers. In order to implement these carbon emissions 
reductions measures, it will be necessary to offset the competitive disadvantages to domestic producers and this will be done through accompanying trade measures. Current proposals in the EU call for systems of tariffs and exports subsidies to compensate both domestic competition and exporters for these border adjustments.

Many issues are raised by these border adjustments including, as in the recent paper by Lockwood and Whalley (2008), the issue of the effectiveness of such measures and whether they will indeed offset the competitive disadvantages, but the pressure in Copenhagen will be for there to be allowable accompanying measures. These, in turn, will create the difficulty that they will likely involve measures which would be in compliance with WTO tariff bindings, and hence build conflict between the environmental regime and the trade regime.

There are also fledgling discussions of various arrangements in the trade area in the form of new regional arrangements. Proposals are beginning to come forward for carbon free trade areas, which might involve tariff and other reductions for the trade of low carbon products and also the use of accompanying measures along the lines of border tax adjustments for groupings of countries.

All of these and also accompanying measures in the financial area may well arise and reflect the pressures that will inevitably build for the crossovers between the new emerging environmental regime and the trade regime in the WTO and the financial regime implicitly underwritten by the IMF to be considered as one single linked entity. In essence, the global policy regime, in terms of policy coordination linking economies which, coming out of the Bretton-Woods Conference of the 1940's, was seen as only involving trade in goods and links in finance, will inevitably be broadened to also include physical interaction between economies. The discussion of regimes for their physical interaction cannot logically take place independently of the trade and finance regimes and this is now reflected in the pressures now occurring in the accompanying measures. 


\subsection{The Size and Administration of Accompanying Funds}

As we note above, the post-Bali Roadmap and Copenhagen negotiation calls for explicit negotiations on both adaptation and innovation funds. The Adaptation Fund ${ }^{17}$ was mandated in the Bali Roadmap, and funds for the other three pillars have rapidly emerged from various sources, notably the World Bank's relatively new Clean Technology Fund (CTF) ${ }^{18}$ and Strategic Climate Fund (SCF) $)^{19}$. These, added to the other World Bank administrated climate change funds currently account for a source of roughly \$20 billion USD annually, which constitutes the majority of international climate change investment funds (although much of it is already dedicated to ongoing projects). These compare to the next two largest sources, the officially mandated Adaptation Fund, whose value, while somewhat uncertain (since it is based on the successes of CDM projects), is at the worst estimated to be worth $\$ 160$ million USD annually and at very best $\$ 960$ million annually ${ }^{20}$, and to the climate change investment program of the Inter-American Development Bank, which accounts for funds of roughly $\$ 6.6$ billion USD annually for various climate change projects. ${ }^{21}$ These funds are seen as facilitating the adaptation of individual countries and economies to climate change and also facilitating the emergence of new technologies to deal with climate change and its effects. Inevitably however, de facto this means that the negotiation which takes place in Copenhagen is a negotiation on simultaneous emissions reductions, with instruments and depth of commitments to be

\footnotetext{
${ }^{17}$ The Adaptation Fund is largely for projects in the areas of the world where climate change will first be felt, so as to lessen the impact of climate change over time. Also, within that group, primary attention is given to developing countries and so, in practice, much of the resources for the Fund come from CDM projects.

${ }_{18}^{18}$ The CTF is largely for research in green technologies and energy. However, in keeping with the World Bank's strengths, the main crux of the fund is that it offers both a short term action plan for carbon reduction that largely focuses on energy efficiency and a green development plan in the longer term based on deploying green energy technologies. As previously stated, the estimated eventual size of the CTF is roughly $\$ 30$ billion USD, with $\$ 5$ billion initially used to get it moving.

${ }^{19}$ The SCF is a pool of funds meant to fund some specific WB sanctioned projects such as a developing country adaptation program as well as a project aimed at forest preservation \& renewal. Otherwise, it's primary purpose is to serve as a source of financing tools such as loans, credits, grants, etc. for the needs of developing countries.

${ }^{20}$ Müller (2007) "The Nairobi Climate Change Conference: A breakthrough for adaptation funding," http://www.oxfordenergy.org/pdfs/comment 0107-1.pdf

${ }^{21}$ Many smaller international funds are managed by GEF. See http://www.gefweb.org/uploadedFiles/Documents/LDCFSCCF_Council_Documents/LDCFSCCF4_April 2008/LDCF.SCCF.4.Inf.2\%20Trustee\%20Status\%20Report\%2003.21.08.pdf for the current status report for these funds.
} 
negotiated along with financial arrangements which involve financial transfers. While not explicitly stated in this way in the post-Bali Roadmap documents, the transfer of funds can be viewed as a form of financial compensation, side payments effectively, between economies which will facilitate the introduction of a system of commitments. As we note above, for the low wage, rapidly growing economies, an interpretation of 'common yet differentiated responsibilities' would suggest that financial compensation for environmental restraint would be an accompanying component of the negotiation and, de facto, the funds which are specified as part of the post-Bali Roadmap have this element in terms of their implementation. Both the size and use of the funds will therefore be a central element in the negotiation.

\subsection{Other Issues in the Negotiation}

Along with the issues we note above, there are some further issues which will likely arise in the negotiation. While individually perhaps less central than those we discuss above, these and others will take on special significance as they interact with the major negotiating issues identified above.

\section{7. a Enforcement and Dispute Settlement}

One is the issue of enforcement and dispute settlement. As mentioned above, Kyoto's enforcement mechanisms have proven largely inadequate and the need for more effective enforcement mechanisms will undoubtedly motivate research as to what these mechanisms could be. One mechanism would be a pre-commitment by negotiating parties to give funds to a central entity, such as an international agency, where they would be held in escrow pending the compliance with negotiated commitments, with an arrangement perhaps that if certain countries were in non-compliance, then these countries would not receive a return of funds and their contribution would be distributed

among the countries who were in compliance, presumably proportionately to GDP or size. 
The size of such a fund would almost inevitably have to be large in order to have an effective dispute settlement mechanism and there would have to be procedures specified for the determination of their compliance at the end of the agreement period. Some such mechanism however, would seemingly inevitably be part, both of the negotiation and a central part of the achievement of an implementable scheme.

\section{7.b Coalitions in the Copenhagen Negotiation}

A final issue concerns both the evolution of coalitions and the negotiating form and how coalitions can indeed both evolve and negotiate within this structure. The typical GATT and WTO negotiations in the trade area have usually been dominated by large entities and communication of outcomes to small entities later on in the negotiating process, with an extension of their negotiating commitments, through MFN, to the smaller parties. This has effectively allowed a structure to evolve in the trade area where the larger countries, through negotiating rounds, have undertaken more significant commitments, extended by MFN to the smaller parties who, to a large degree, free ride on the multilateral commitment, although they have incentives of their own to more firmly undertake unilateral actions.

In the environmental area, the coalitional structure will inevitably be different and will come into play in a central way and the question is both how this operates in terms of modalities of negotiation and whether it will significantly affect the outcomes of the negotiations. Already there is a coalition of small independent island states, the Alliance of Small Island States (AOSIS), who negotiate together. The negotiating interests of India, China, Russia and Brazil are clearly aligned, particularly for China, India and Brazil and a negotiating coalition will almost certainly emerge there.

The coalitional structure that emerges may or may not aid to conclude the negotiations. In theory, more coalitions would equate to fewer parties with opposing positions at the final negotiations in Copenhagen, which in turn, should lead to a faster resolution and conclusion to the negotiation. This basic assessment, however, fails to factor in the relative inexperience of all parties to the negotiation in environmental issues 
and as scientific facts emerge and/ or are reassessed, the stability of some of the coalitions that emerge may come into question, especially as the stakes change in regards to the increasing (or decreasing) perceived threat posed by climate change to any specific geographic region.

To the extent that these key negotiating coalitions emerge and if negotiations take place between groups of countries such as between the OECD and between India, China and Brazil, that can facilitate negotiation, but it can also complicate it due to the difficulty of obtaining and retaining common coalitional positions. On the other hand, it could also be the case that the negotiations are far to complex to conclude at Copenhagen without an established coalitional structure. It may also turn out to be the case that a mechanism to give a specific deadline, such as the expiry of US negotiator fast track authority in WTO trade rounds, is needed to give the momentum needed to move the negotiation to a conclusion. 


\section{Can Copenhagen Conclude with Significant Content?}

In this section, we discuss potential scenarios for the conclusion of the Copenhagen negotiation and identify both obstacles and also positive elements which can affect the outcome in more positive ways. This negotiation, as we mentioned above, has a very short time frame and is imprecise in terms of its current negotiating mandate. It is also a negotiation being conducted largely within UN agencies which have limited experience or prior involvement in international negotiation and whose reach into international bureaucracies is largely into environmental agencies, rather than agencies such as in the trade area, where there is an accumulated reservoir of negotiating talent and experience.

For all of these reasons therefore, there has been substantial skepticism in many of the circles close to these negotiations in terms of it's potential ability to conclude.

\subsection{Obstacles to Negotiation}

We identify a series of potential obstacles to a satisfactory conclusion to the negotiation. Undoubtedly, the political pressures on the negotiation will be such that there will be some kind of an agreement with a declared outcome and some have suggested that, de facto, any significant progress on climate change, if it occurs, is likely to happen not within the Copenhagen process, but within the G8+5 process of the 8 large OECD countries plus the 5 large, low income, rapidly growing economies, since the highest global emitters (on a level basis) are concentrated within this group of 13 countries. But the obstacles to the negotiation are, unfortunately, many. One is the central issue of the imprecision of the negotiating mandate. There is a mandate to negotiate on emissions reductions; the instruments to be used in that negotiation are unclear and unresolved. The time frame for the mandate is unclear and all of this lack of precision inevitably means that these matters have to be resolved before a negotiation can conclude. Another is the fact that this is, by nature, a collective action problem and the incentive for any one individual country to participate, particularly in the case of small countries, is small. That 
is, unless all (or most) countries participate in the negotiation and agreement, the costs to any individual participating country incurred by internalizing greenhouse gas emissions and other climate change causing elements may outweigh the actual environmental gains from doing so.

\section{1. a Lack of a Clear Deadline}

In the trade area, the experience has been typically that the negotiations go down to the wire, with the decisions only made in the last few days and few hours, with maneuvering for position going on for many years, then a last minute of frantic posturing before deals are concluded. As such, the imprecision of the mandate can be a major factor in preventing a successful conclusion to the negotiation simply because of the ambiguity of what is being negotiated on and, if this were to continue up to the final stages of the Copenhagen negotiation, and if this negotiation mimics past trade negotiations in this way, it represents a major difficulty.

\section{1.b Unfulfilled Commitments}

In addition, there is the backlog of unfulfilled commitments that we mentioned above. This will be a major difficulty and obstacle to the negotiation in the sense that those countries and economies with a backlog of unfulfilled commitments would be reluctant to take on any new commitments if the new treaty were to indicate that they must still clear away their backlog as well. On the other hand, those parties to the negotiation not in this situation will continually use this as a major pressure on those economies. The difference for some of the OECD countries, such as Canada, in accepting the backlog or not could be more important than the commitments they take on as part of the Copenhagen negotiation itself. So, rather than just the presence of a backlog, it is the quantitative size of these backlogs which would be a further complication to the negotiation. This will have the effect of splitting the countries in the negotiation into 
those with and without backlogs, which is a situation quite similar to the negotiations on the issue of the time frame and the base date for the emissions reduction commitments.

\section{1.c Constraints from Non-Climate Change Issues}

A further central difficulty is the emerging issue of accompanying measures, and measures specifically in the trade area. These measures, in our opinion, reflect what is the natural logical evolution of an emerging global policy regime, which not only concerns the environmental area, but also explicitly links environment and trade. Whether or not the negotiations formally acknowledge the linkage, de facto, the linkage will be there and will be central and will grow. This linkage is such that, effectively, trade and environment must be linked in order to achieve a satisfactory outcome both to environmental negotiations and also to trade negotiations in the presence of environmental considerations. The impact of one negotiation on the other will be central and pivotal in terms of the need to achieve global environmental improvements. What these accompanying measures would be, how they would operate and so on would therefore become an increasingly central part of the Copenhagen negotiation going forward and would deflect attention from the direct negotiation on emissions reduction and the use of funds. But, should this linkage not be acknowledged, the prospect is of a world that would go both green and protectionist at the same time, with the accompanying difficulties associated with that.

A final central obstacle is the interpretation of 'common yet differentiated responsibilities', which we note above. With the two interpretations, of the need for financial compensation to compensate countries whose commitments impinge on their growth and development, and the other interpretation of the use of different commitments in negotiation for countries differing by levels of income, obtaining agreement on all these matters represents a substantial obstacle. 


\subsection{Factors Driving a Successful Conclusion}

Having noted the obstacles, it is also the case that there are significant pressures which would point towards a conclusion of a round, and it is possible that these pressures could overcome the many obstacles which we identify above. Whether this will be the case depends upon the outcomes achieved.

First, and absolutely key, is the perception of the severity of the issue of climate change. There is a perception now, which is widely shared in some circles, that not only is climate change a widely significant problem, but is also one that is growing in severity much more rapidly than many people understand and/or appreciate. This is the position which has recently been taken by Nicholas Stern. It is associated with those who argue that the rate of melt of Arctic sea ice is much more dramatic than is indicated in the latest IPCC report, and that the melt of Arctic glaciers may now be occurring up to 8 times the rate it was occurring at 10 years ago. ${ }^{22}$

All of these are indications of a rapidly escalating severity of climate change issues in terms of popular perception, and to the extent that this is so, the pressure towards a successful negotiation on politicians would grow and could lead to a more positive outcome from the Copenhagen negotiation.

However, on the other hand are the ones who have called themselves 'climate change rationalists', who have often been labeled in the media as climate change skeptics or deniers. This group of scientists exists to pick apart and analyze such popular climate change works as the IPCC reports and the Stern Review (2007) and, for the most part, they have found huge inconsistencies between what the empirical science that they work with tells them and what the computer generated forecasting models highlighted in these internationally renowned reports indicate. Ultimately, their view boils down to stating that, yes, we are currently warming, but we have not warmed enough or over a long enough period of time for it to be a statistically significant event. Both the level of warming and the rate of change are still within the bounds of natural variability as seen by the temperature record for the past 12000 years (since the last ice age). Added to this is their view that the atmospheric models used in such reports as the IPCC's fourth

\footnotetext{
${ }^{22}$ See http://www.planetark.com/dailynewsstory.cfm/newsid/27332/newsDate/24-Sep-2004/story.htm
} 
assessment report (AR4) are overly simplistic, even given what little we know of how our atmosphere functions. Also key in their stance is the non-controversial fact that $\mathrm{CO}_{2}$ has an effect on atmospheric temperature that levels off logarithmically at higher concentrations, meaning that there is an effective upper bound to the effect it can contribute to climate change, and that we are already at a point that it would require slightly more than a doubling of atmospheric $\mathrm{CO}_{2}$ in order to cause an additional temperature increase of just 1 degree $C{ }^{23}$ If this view of climate change emerges within the Copenhagen negotiating process then the incentives to move the negotiation forward to a conclusion may decrease, especially in the area of $\mathrm{CO}_{2}$ reduction initiatives, despite any indicative events to the contrary such as accelerating Arctic melt.

A second issue moving the negotiations towards a conclusion is the clear and growing desire on the part of many countries involved and participating in these negotiations to use their participation to underpin their global co-operational policy from elsewhere; and hence, along with this, a perceived penalty which many countries would have from their non-participation in these international negotiations, were there to be an outcome. This seems especially clear in the Chinese case and China has been following a growth and development path since the 1990's which is fundamentally trade oriented, with a rapid export growth of 30\% per year in recent years and large growth of inward foreign direct investment to fuel the export growth. China's integration into the global economy has become the central plank of Chinese growth. In order to maintain openness to markets abroad and facilitate Chinese growth and development, China therefore sees it centrally in her interest to be a significant and active partner in international cooperation, including in the environmental area. Hence, China's objectives in the environmental area are not only simply environmental, they are to maintain the openness of the trade regime. This argument applies, albeit perhaps more weakly so, in the case of India, Brazil and other economies and even in the case of the higher income OECD economies. The central interest in maintaining an open policy regime in areas outside of the environment can therefore act as a significant incentive to achieve compliance in the environmental area.

\footnotetext{
${ }^{23}$ Based on a lecture given by Professor Bob Carter of the Marine Geophysical Laboratory at James Cook University, Australia. (see http://scienceandpublicpolicy.org/videos/bobcarter.html)
} 
Hence, the conclusion of the Copenhagen negotiation faces a whole series of more narrowly focused and more problematic matters concerning the imprecision of the mandate, the basic science, the backlog of commitments, the use of accompanying measures, and the interpretation of 'common yet differentiated responsibilities' along with a host of more positive factors including the growing severity of the issues, the desire in many circles to achieve international policy cooperation in areas outside of the environment and the changing political landscape in the US. 


\section{Beyond Copenhagen \& Concluding Remarks}

The conclusion of the Copenhagen negotiation, in our view, then not only depends upon what happens in the actual negotiation itself, but will also reflect the expectation of future negotiations beyond Copenhagen. The presumption, much as in the trade regime and the WTO/GATT process, is that, through a sequence of international negotiations stretching out over many decades, there will be a progressive move globally towards a global environmental regime which will reflect policy cooperation and policy coordination to deal centrally with the internalization of externalities associated with

global warming based on the presumption that the earth sciences have correctly identified the prospect of major damage affecting national economies and hence this internalization takes place. As a result, the Copenhagen negotiation may rightly be viewed as only one step in a series of sequential rounds, such as exists in the trade case. Thus a factor in the negotiation will be the view that participation in Copenhagen is participation in a process similar to that currently ongoing in trade and the experience in the trade area indicates that countries which withdrew from negotiation at an early stage in the sequence then found it difficult and problematic to re-enter this negotiating sequence - the classic case being China, who withdrew from the GATT in 1949 and had to undergo complex negotiations on resumption of a WTO membership through accession concluding in 2001. As a result, the 'beyond Copenhagen' scenarios will affect Copenhagen's outcomes, perhaps especially in regards to the time frame of any post-2012 agreements made.

The most likely future scenarios, using the trade experience as a precedent, would seem to involve 3 central elements. The first is the broadening of negotiations sequentially across rounds. In the trade area, the broadenings occurred initially from tariffs into other trade related instruments such as subsidies and then, in the Uruguay Round, into a whole series of further issues including intellectual property, investment and arrangements in agriculture, textiles and elsewhere. A similar broadening seems likely to occur in the global environmental area, with other environmental issues being added to the climate change agenda even though climate change would remain as a central element of the negotiation, with energy related issues also intruding. This could include international codes on nuclear, or the disposal of wastes, as in the Basel 
Convention. The linking of the patchwork quilt of international conventions which have emerged in the international area over the years, as identified by Whalley and Zissimos (2001), and would involve perhaps 150 ad hoc treaties. Whether this would eventually lead to a broadened form of world environmental organization would remain to be seen.

The second element in future rounds would seemingly involve the growing links to other elements of the international policy regime, particularly in the trade and finance areas. As we note above, the current global situation still reflects an institutional form in a time warp of the 1940's, based on arrangements underpinning trade and finance as linkages between economies, but ignoring their physical interaction in the environmental area. Now, with the growth of global negotiations on climate change, we have the emergence of agreements on an environmental regime, raising the issue of linkage to trade and finance. But in turn, the negotiations in trade and finance will have to be linked in terms of their potential impacts on climate change. Eventually, these two separate sets of negotiations would seemingly need to be jointly linked, with joint bargaining across trade, finance, and global environment and how that joint bargaining would occur, whether it would evolve out of the WTO or by some other means, would also be a central issue.

Finally, we have the issue of the institutional form for such negotiations. The current round for climate change negotiations has taken place under the UN and the UN Framework Convention on Climate Change (UNFCCC), which in turn, has involved the three central entities of UNEP, WMO, and the IPCC. There are many deficiencies in these institutional arrangements, as has been widely noted in literature. The World Meteorological Organization is not an organization centrally designed to achieve internalization of externalities. The IPCC is a body whose legitimacy, in terms of national membership, is one which has been questioned and, generally, the use of UN agencies in relatively remote geographical areas, with relatively small numbers of employees and limited expertise in international negotiation (such as UNEP) is something which has been queried in terms of its satisfactory nature relative to the task at hand.

In turn, the issue arises as to whether or not the WTO itself will transform and change itself from a world trade organization to, effectively, a world bargaining organization, building on its prior experience and involvement in trade bargaining to 
become a form of world bargaining organization into which environmental issues will be inserted in bargaining format, with the transference of the bargaining we see in the current Bali \& Copenhagen Rounds.

Whether these developments will occur remains to be seen but they will also affect the outcome in Copenhagen. 


\section{Bibliography}

Barrett, S. (1992), "Strategy and the environment", Columbia Journal of World Business, Vol. 27 No.3/4, pp.202-8.

Bruntland, G. (ed.) (1987), Our Common Future: The World Commission on Environment and Development, Oxford: Oxford University Press.

Carrero, C. \& D. Siniscalco (1995), "Policy coordination for sustainability", in Goldin, I., Winters, L.A. (Eds), The Economics of Sustainable Development, Cambridge University Press, Cambridge, pp.264-82.

Carson, Rachel (1962), Silent Spring, Boston: Houghton Mifflin.

Carter, Robert (2007) Lecture: Global Warming - is $\mathrm{CO}_{2}$ the Cause?, James Cook University, Australia. (video record: $\underline{\mathrm{http}: / / \text { scienceandpublicpolicy.org/videos/bobcarter.html) }}$

Foster, Peter (May 12, 2007) "India Snubs West on Climate Change,” The Telegraph, http://www.telegraph.co.uk/earth/main.jhtml?xml=/earth/2007/06/12/eaindia12.x $\underline{\mathrm{ml}}$, (accessed Sept. 2, 2008).

Global Leadership for Climate Action (2007), Framework for a Post-2012 Agreement on Climate Change, Club of Madrid and UN Foundation.

International Energy Agency (2008), Energy Technology Perspectives 2008: Scenarios and Strategies to 2050, IEA.

International Panel on Climate Change (IPCC) (2007), "Summary for Policymakers of the Synthesis Report of the IPCC Fourth Assessment Report".

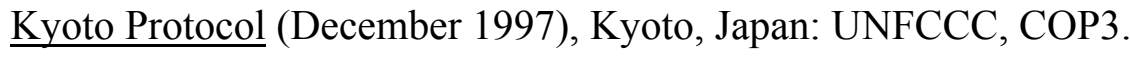

Lewis, J. \& E. Diringer (2007), "Policy-Based Commitments in a Post-2012 Climate Framework" Working Paper, PEW Center on Climate Change.

Lockwood, Benjamin \& John Whalley (2008), "Carbon Motivated Border Tax Adjustments: Old Wine in Green Bottles?” NBER Working Paper Series, No. 14025.

Lodefalk, M. \& J. Whalley (2002), "Reviewing Proposals for a World Environmental Organization”, World Economy, Vol. 25, no. 5, pp. 601-617.

Lovelock, James (2006), The Revenge of Gaia: Why the Earth Is Fighting Back - and How We Can Still Save Humanity, Santa Barbara (California): Allen Lane. 
Mendelsohn, Robert, O (2006), "A Critique of the Stern Report," Regulation, (Winter 2006-2007), pp.42-46.

Müller, Benito (2007), “The Nairobi Climate Change Conference: A breakthrough for adaptation funding," Oxford Energy \& Environment Comment, http://www.oxfordenergy.org/pdfs/comment 0107-1.pdf, accessed Sept. 10, 2008.

Nash, J. (1951), “Non-Cooperative Games” Annals of Mathematics, 54, pp 286-295.

Nordhaus, W. (2007), The Challenge of Global Warming: Economic Models and Environmental Policy, New Haven, CT: Yale University.

Planet Ark (Sept. 24, 2004), “Antarctic Glaciers Melting Faster - Study”, http://www.planetark.com/dailynewsstory.cfm/newsid/27332/newsDate/24-Sep2004/story.htm, (accessed Sept. 15, 2008)

Sinn, Hans-Werner (2007), "Public Policies Against Global Warming” CESifo Working Paper Series, Category 8: Resources and Environment, WP No. 2087.

Stern, N. H. et al (2006), The Stern Review, UK Government.

Sugiyama, T. (ed.) (2005), Governing Climate: The Struggle for a Global Framework Beyond Kyoto; Hamburg: Fridtjof Nansen Institute.

Walsh, Sean \& John Whalley (2008), "The Global Negotiating Framework for Climate Change Mitigation"(unpublished), http://www.cigionline.org/community.igloo? $\mathrm{r} 0=$ communitydownload\&r0_script $=/$ scripts/document $/$ download. script\& $\mathrm{r} 0 \_$pathinfo $=\% 2 \mathrm{~F} \% 7 \mathrm{~B}$ 7caf3d23-023d-494b-865b84d143de9968\%7D\%2FResearch\%2Fglobalse $\% 2$ Fglobalen $\% 2$ Fconferen $\% 2 F$ cha 1leng\%2Fjohnwhal\&r0 output $=$ xml.

Whalley, John \& Ben Zissimos (2000), "Trade and Environment Linkage and a Possible World Environmental Organisation" Environment and Development Economics, Vol. 5, Issue 4 (October), pp. 510-516.

Whalley, John \& Ben Zissimos (2001), "What Could a World Environmental Organization Do?” Global Environmental Politics, Vol. 1, Issue 1 (February), pp. 29-34. 


\section{CESifo Working Paper Series}

for full list see www.cesifo-group.org/wp

(address: Poschingerstr. 5, 81679 Munich, Germany, office@cesifo.de)

2397 Mohammad Reza Farzanegan, Illegal Trade in the Iranian Economy: Evidence from a Structural Model, September 2008

2398 Olivier Bos, Charity Auctions for the Happy Few, September 2008

2399 Robert S. Chirinko and Debdulal Mallick, The Marginal Product of Capital: A Persistent International Puzzle, September 2008

2400 Ben D'Exelle and Arno Riedl, Elite Capture, Political Voice and Exclusion from Aid: An Experimental Study, September 2008

2401 Torben M. Andersen and Joydeep Bhattacharya, On Myopia as Rationale for Social Security, September 2008

2402 Fabienne Llense, French CEO Compensations: What is the Cost of a Mandatory Upper Limit?, September 2008

2403 Valentina Bosetti, Carlo Carraro, Alessandra Sgobbi and Massimo Tavoni, Delayed Action and Uncertain Targets. How Much Will Climate Policy Cost?, September 2008

2404 Robert G. Chambers, Rolf Färe, Shawna Grosskopf and Michael Vardanyan, Generalized Quadratic Revenue Functions, September 2008

2405 Leonidas Enrique de la Rosa, Overconfidence in a Career-Concerns Setting, September 2008

2406 Marcus Drometer and Johannes Rincke, The Design of Political Institutions: Electoral Competition and the Choice of Ballot Access Restrictions in the United States, September 2008

2407 Markku Lanne and Helmut Lütkepohl, Stock Prices and Economic Fluctuations: A Markov Switching Structural Vector Autoregressive Analysis, September 2008

2408 Thomas L. Brewer, International Energy Technology Transfers for Climate Change Mitigations, September 2008

2409 Alexander Kemnitz, Native Welfare Losses from High Skilled Immigration, September 2008

2410 Xavier Vives, Strategic Supply Function Competition with Private Information, September 2008

2411 Fabio Padovano and Roberto Ricciuti, The Political Competition-Economic Performance Puzzle: Evidence from the OECD Countries and the Italian Regions, September 2008 
2412 Joan Costa-Font and Mireia Jofre-Bonet, Body Image and Food Disorders: Evidence from a Sample of European Women, September 2008

2413 Thorsten Upmann, Labour Unions - To Unite or to Separate?, October 2008

2414 Sascha O. Becker and Ludger Woessmann, Luther and the Girls: Religious Denomination and the Female Education Gap in $19^{\text {th }}$ Century Prussia, October 2008

2415 Florian Englmaier and Stephen Leider, Contractual and Organizational Structure with Reciprocal Agents, October 2008

2416 Vittorio Daniele and Ugo Marani, Organized Crime and Foreign Direct Investment: The Italian Case, October 2008

2417 Valentina Bosetti, Carlo Carraro, Alessandra Sgobbi and Massimo Tavoni, Modelling Economic Impacts of Alternative International Climate Policy Architectures. A Quantitative and Comparative Assessment of Architectures for Agreement, October 2008

2418 Paul De Grauwe, Animal Spirits and Monetary Policy, October 2008

2419 Guglielmo Maria Caporale, Christophe Rault, Robert Sova and Anamaria Sova, On the Bilateral Trade Effects of Free Trade Agreements between the EU-15 and the CEEC-4 Countries, October 2008

2420 Yin-Wong Cheung and Daniel Friedman, Speculative Attacks: A Laboratory Study in Continuous Time, October 2008

2421 Kamila Fialová and Ondřej Schneider, Labour Market Institutions and their Effect on Labour Market Performance in the New EU Member Countries, October 2008

2422 Alexander Ludwig and Michael Reiter, Sharing Demographic Risk - Who is Afraid of the Baby Bust?, October 2008

2423 Doina Maria Radulescu and Michael Stimmelmayr, The Welfare Loss from Differential Taxation of Sectors in Germany, October 2008

2424 Nikolaus Wolf, Was Germany ever United? Evidence from Intra- and International Trade 1885 - 1933, October 2008

2425 Bruno S. Frey, David A. Savage and Benno Torgler, Noblesse Oblige? Determinants of Survival in a Life and Death Situation, October 2008

2426 Giovanni Facchini, Peri Silva and Gerald Willmann, The Customs Union Issue: Why do we Observe so few of them?, October 2008

2427 Wido Geis, Silke Uebelmesser and Martin Werding, Why go to France or Germany, if you could as well go to the UK or the US? Selective Features of Immigration to four major OECD Countries, October 2008 
2428 Geeta Kingdon and Francis Teal, Teacher Unions, Teacher Pay and Student Performance in India: A Pupil Fixed Effects Approach, October 2008

2429 Andreas Haufler and Marco Runkel, Firms' Financial Choices and Thin Capitalization Rules under Corporate Tax Competition, October 2008

2430 Matz Dahlberg, Heléne Lundqvist and Eva Mörk, Intergovernmental Grants and Bureaucratic Power, October 2008

2431 Alfons J. Weichenrieder and Tina Klautke, Taxes and the Efficiency Costs of Capital Distortions, October 2008

2432 Andreas Knabe and Ronnie Schöb, Minimum Wage Incidence: The Case for Germany, October 2008

2433 Kurt R. Brekke and Odd Rune Straume, Pharmaceutical Patents: Incentives for R\&D or Marketing?, October 2008

2434 Scott Alan Carson, Geography, Insolation, and Institutional Change in $19^{\text {th }}$ Century African-American and White Stature in Southern States, October 2008

2435 Emilia Del Bono and Daniela Vuri, Job Mobility and the Gender Wage Gap in Italy, October 2008

2436 Marco Angrisani, Antonio Guarino, Steffen Huck and Nathan Larson, No-Trade in the Laboratory, October 2008

2437 Josse Delfgaauw and Robert Dur, Managerial Talent, Motivation, and Self-Selection into Public Management, October 2008

2438 Christian Bauer and Wolfgang Buchholz, How Changing Prudence and Risk Aversion Affect Optimal Saving, October 2008

2439 Erich Battistin, Clara Graziano and Bruno Parigi, Connections and Performance in Bankers' Turnover: Better Wed over the Mixen than over the Moor, October 2008

2440 Erkki Koskela and Panu Poutvaara, Flexible Outsourcing and the Impacts of Labour Taxation in European Welfare States, October 2008

2441 Marcelo Resende, Concentration and Market Size: Lower Bound Estimates for the Brazilian Industry, October 2008

2442 Giandomenico Piluso and Roberto Ricciuti, Fiscal Policy and the Banking System in Italy. Have Taxes, Public Spending and Banks been Procyclical in the Long-Run? October 2008

2443 Bruno S. Frey and Katja Rost, Do Rankings Reflect Research Quality?, October 2008

2444 Guglielmo Maria Caporale, Antoaneta Serguieva and Hao Wu, Financial Contagion: Evolutionary Optimisation of a Multinational Agent-Based Model, October 2008 
2445 Valentina Bosetti, Carlo Carraro and Massimo Tavoni, Delayed Participation of Developing Countries to Climate Agreements: Should Action in the EU and US be Postponed?, October 2008

2446 Alexander Kovalenkov and Xavier Vives, Competitive Rational Expectations Equilibria without Apology, November 2008

2447 Thiess Buettner and Fédéric Holm-Hadulla, Cities in Fiscal Equalization, November 2008

2448 Harry H. Kelejian and Ingmar R. Prucha, Specification and Estimation of Spatial Autoregressive Models with Autoregressive and Heteroskedastic Disturbances, November 2008

2449 Jan Bouckaert, Hans Degryse and Thomas Provoost, Enhancing Market Power by Reducing Switching Costs, November 2008

2450 Frank Heinemann, Escaping from a Combination of Liquidity Trap and Credit Crunch, November 2008

2451 Dan Anderberg, Optimal Policy and the Risk Properties of Human Capital Reconsidered, November 2008

2452 Christian Keuschnigg and Evelyn Ribi, Outsourcing, Unemployment and Welfare Policy, November 2008

2453 Bernd Theilen, Market Competition and Lower Tier Incentives, November 2008

2454 Ondřej Schneider, Voting in the European Union - Central Europe's Lost Voice, November 2008

2455 Oliver Lorz and Gerald Willmann, Enlargement versus Deepening: The Trade-off Facing Economic Unions, November 2008

2456 Alfons J. Weichenrieder and Helen Windischbauer, Thin-Capitalization Rules and Company Responses, Experience from German Legislation, November 2008

2457 Andreas Knabe and Steffen Rätzel, Scarring or Scaring? The Psychological Impact of Past Unemployment and Future Unemployment Risk, November 2008

2458 John Whalley and Sean Walsh, Bringing the Copenhagen Global Climate Change Negotiations to Conclusion, November 2008 